\title{
OBITUARY Professor Stephen Bishop
}

It was with great sadness that we learned of the death of Stephen Bishop in April. Steve had been on the Editorial Board of the Journal since 2000 and his support was greatly appreciated. There follows an obituary written by his colleagues at Roslin Research Institute, Alan Archibald and David Hume. Our thoughts are with his friends and family. He will be greatly missed.

\section{JULIAN WISEMAN and PAUL BILSBORROW Senior Editors}

Professor Stephen Bishop passed away peacefully on 2 April 2015 a few short weeks after being diagnosed with a brain tumour.

Stephen Bishop (Steve) was an influential scientist, known and respected world-wide. He made an outstanding contribution to our understanding of the impact of host genetics on infectious disease outcomes in farmed animals at the individual and population level. In particular, he introduced epidemiological concepts into the field of quantitative genetics and successfully demonstrated the application of these concepts to several diseases. Steve and his colleagues identified loci associated with increased resistance using molecular genetic data for several diseases, notably nematode infections in sheep, bovine tuberculosis, porcine reproductive and respiratory syndrome and infectious pancreatic necrosis in Atlantic salmon.

As well as laying the theoretical foundations for breeding programmes for nematode resistance in sheep, supported by extensive experimentation, he identified a major locus determining survival/mortality following viral challenge in farmed salmon. This latter success was in close collaboration with a Scottish commercial salmon breeding company and has been applied by them in commercial production in Scotland and Chile to great effect. It is generally regarded as possibly the most successful example of genetic control of disease resistance in any livestock species.

Steve graduated from Lincoln College in New Zealand with an Honours degree in Agricultural Science in 1982 before coming to Edinburgh as a
Commonwealth Scholar to study for a Ph.D. in 'Genetic and metabolic aspects of growth and its components in mice' under the supervision of Professor William Hill. Professor Hill recalls Steve constructing a working calorimeter for mice of which Heath Robinson would have been proud. After completing an excellent Ph.D. without apparent stress in 1985, Steve moved to the Technical University of Munich as a post-doctoral scientist before returning to his native New Zealand to work as a geneticist for the Livestock Improvement Corporation.

In 1988 he joined the AFRC Institute of Animal Physiology and Genetics Research in Edinburgh, which in 1993 evolved into the Roslin Institute and subsequently integrated into the University of Edinburgh in 2008. Steve established himself as an independent research leader, was awarded a Research Council Individual Merit Promotion in 2002 and a Personal Chair in Animal Disease Genetics at the University of Edinburgh in 2009. He was also recognized as a Visiting Professor (University of Glasgow) and a Special Professor (University of Nottingham). He was awarded the prestigious Hammond Memorial Prize in 2009 by the British Society of Animal Science. Subsequently he was elected a Vice-President of the Society and was due to assume the role of President in April 2015. He served on the International Organising Committee for the World Congress on Genetics Applied to Livestock Production and as an editor for several scientific journals, including the Journal of Agricultural Science, Cambridge.

Steve was a successful and productive scientist. He published about 200 refereed scientific papers, more than 300 conference papers and edited four books. He won competitive research grants from Research Councils, Ministry of Agriculture, Food and Fisheries, Technology Strategy Board, European Commission, industrial players in the livestock sector and charities.

His research was both scientifically innovative and had impact. Most recently, together with Ross Houston he was runner up in the BBSRC Innovator of the Year Award for their work on genetics of susceptibility to infectious pancreatic necrosis in Atlantic salmon. 
These are some of the dry facts about Steve's work and career, but they tell only part of his life's story.

Steve was a generous and diligent mentor to many postgraduate students and young post-doctoral research scientists. This quality was formally recognized when he won the Institute's 'Inspiring Mentor award' in 2014. His inspirational leadership marked the professional career of many young and established scientists in animal genetics, who now carry his scientific ideas forward. He collaborated with colleagues within the institute, locally, nationally and across the world. To name a few countries, India, Canada, USA, Brazil, South Africa, France, Botswana, Australia, New Zealand, Chile, Italy, Spain. When news of Steve's illness broke, messages of concern and warm tributes flooded in from across the world and several of his collaborators travelled from overseas to visit him.

Steve had a dry sense of humour and a wry and mischievous outlook on life. He was a talented pianist. He enjoyed sport, was an enthusiastic club tennis player at West Linton and was always keen to share his predictions of the fate of New Zealand cricket and rugby teams, and of course, all their competitors as well. He was a lover of outdoor life including hill walking. He was a warm and generous man whose primary concern was the welfare of his family, friends and colleagues. In the short time between his diagnosis and the rapid deterioration in his health, Steve expressed his concern for the future of his research team and students and contributed to the planning for their futures.

To his students and colleagues, his door was always open. He had time for all, always sympathetic and good-humoured, fair but frank. An exceptional thinker and problem-solver, his advice was treasured by many. He was humble and a great friend. His memory will always live with us.

He is survived by his wife Tarana and daughter Ima. Our thoughts are with them at this difficult time.

ALAN ARCHIBALD AND DAVID HUME

The Roslin Institute and Royal (Dick)

School of Veterinary Studies

University of Edinburgh

Easter Bush

Midlothian EH25 9RG Scotland, UK 